\title{
Routine aortic valve replacement followed by a myriad of complications: role of 3D printing in a difficult cardiac surgical case
}

\author{
Kálmán Benke*, János Imre Barabás*, László Daróczi, Alex Ali Sayour, Bálint Szilveszter, Miklós Pólos, \\ Árpád Lux, Andrea Székely, Tamás Radovits, István Hartyánszky, Béla Merkely, Zoltán Szabolcs \\ Heart and Vascular Center, Semmelweis University, Budapest, Hungary \\ *These authors contributed equally to this work. \\ Correspondence to: Kálmán Benke, MD. Heart and Vascular Center, Semmelweis University, H-1122 Budapest, Városmajor str. 68, Budapest, Hungary. \\ Email: kalman.benke@gmail.com.
}

\begin{abstract}
Aortic valve replacement (AVR) is a routine cardiac surgical intervention that is rarely associated with severe complications. In this report, we present a complex and unique case following AVR in a middleaged woman. We show the growing necessity for a strong cooperation between interventional cardiologists and cardiac surgeons, together with the emerging role of cardiac tomography based three-dimensional printing technique in planning and executing precision surgery within the chest.
\end{abstract}

Keywords: Cardiac surgery; 3D printing technique; aortic valve replacement (AVR); mechanical circulatory support

Submitted Aug 16, 2017. Accepted for publication Oct 12, 2017.

doi: $10.21037 /$ jtd.2017.10.77

View this article at: http://dx.doi.org/10.21037/jtd.2017.10.77

\section{Introduction}

Aortic stenosis (AS) due to calcification is the most frequent valve disease in America and Europe (1). While aortic valve replacement (AVR) is the definitive therapy of severe AS, the advanced age of the affected patients poses increased operative risk. The overall mortality of the procedure is $1-3 \%$, with infection, excessive blood loss, and thromboembolism being the most common complications (2). Here we present a complex case with some of the most severe postoperative complications following AVR.

\section{Case presentation}

A 55-year-old female patient underwent AVR with xenograft implantation (first operation) due to AS, who had no prior apparent coronary artery disease. Following cardiac surgery, the patient was readmitted to our clinic owing to inferior ST-segment elevation myocardial infarction (STEMI). Coronary arteriography showed right coronary artery (RCA) occlusion that necessitated an urgent cardiac surgery with application of intra-aortic balloon pump (IABP, second operation). During the intervention, type A aortic dissection was observed which occluded the right coronary and had to be bypassed with a saphenous vein graft (SVG). However, the reconnection of the left main (LM) was only possible with a Gore-Tex interpositum because of the malignant adhesions. Furthermore the procedure was converted into deep hypothermic circulatory arrest (DHCA) in order to perform open distal anastomosis to the arch. So we ended up with a modified Bentall procedure, whereas the right coronary was bypassed with SVG.

Following surgery, the patient was transferred to intensive care unit (ICU), where postoperative transesophageal echocardiography (TEE) examination revealed deterioration of right ventricular function that was attributable to the previous RCA infarction, hence right ventricular assist device (RVAD) was implanted immediately (third operation).

The right ventricle recovered following 26 days of mechanical circulatory support (MCS), and the patient was successfully weaned from the device. During this (fourth) chest opening, the sternum got infected and negative pressure wound therapy (NPWT) was necessary. Since the sternum has broken apart, we decided to close the chest with laminar sternum-osteosynthesis. Six months later, control computed tomography (CT) angiography described 

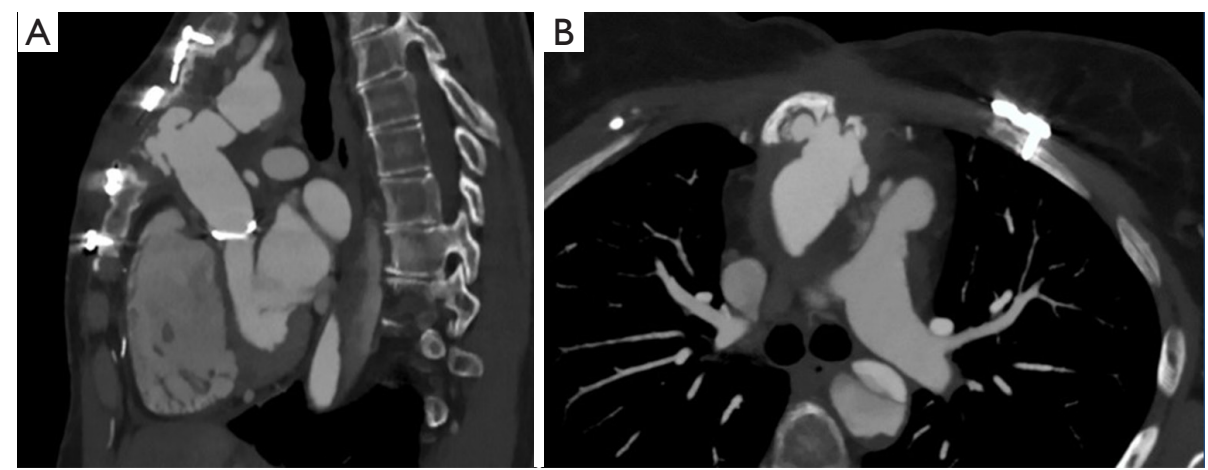

Figure 1 Sagittal (A) and axial (B) computed tomography (CT) images of the heart. The control CT scans show an aortic pseudoaneurysm at the inner side of the anterior chest wall.
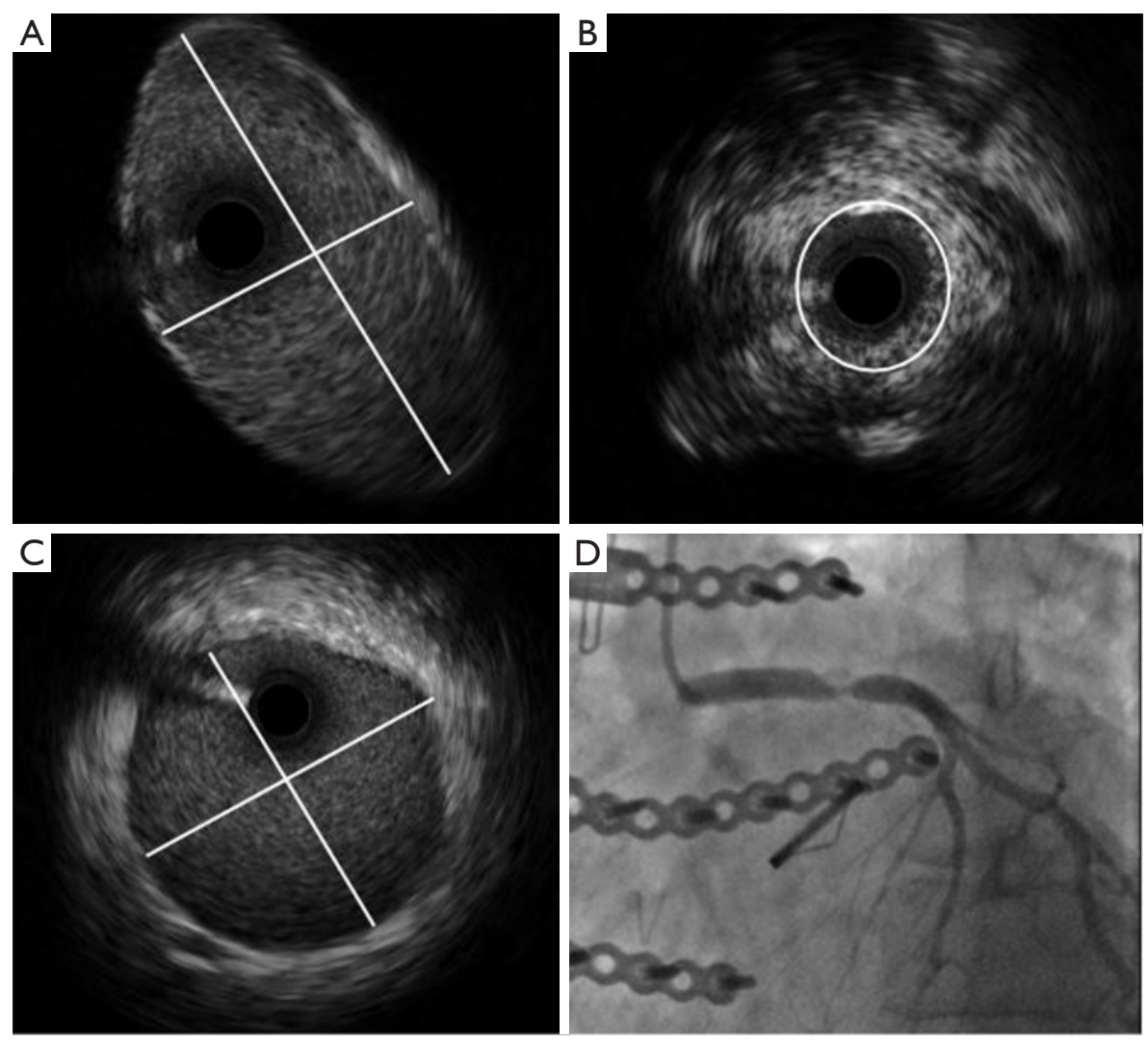

Figure 2 Prior to percutaneous coronary intervention. (A) The inner diameters inside the interpositum $(7.4 \mathrm{~mm} \times 4.0 \mathrm{~mm})$; (B) the white circle marks the minimal lumen area $\left(4.5 \mathrm{~mm}^{2}\right)$; (C) the inner diameter of the native left main $(6.1 \mathrm{~mm} \times 6.1 \mathrm{~mm})$; (D) the angiographic image.

RCA graft occlusion and significant discrepancy of the interpositum-LM diameters. One year later, our patient returned with Canadian Cardiovascular Society (CCS) class III angina and critical stenosis of the LM-graft anastomosis together with a giant aortic pseudoaneurysm revealed on control CT (Figure 1).
Since a repeated surgical revascularization bore immense perioperative risk due to aortic pseudoaneurysm and titanium osteosynthesis, the team decided to perform LMPCI, while the reconstruction of the pseudoaneurysm was postponed. Angiographic evaluation showed a short, nonbifurcating lesion, with a diameter of $6 \mathrm{~mm}$ (Figure 2). After 

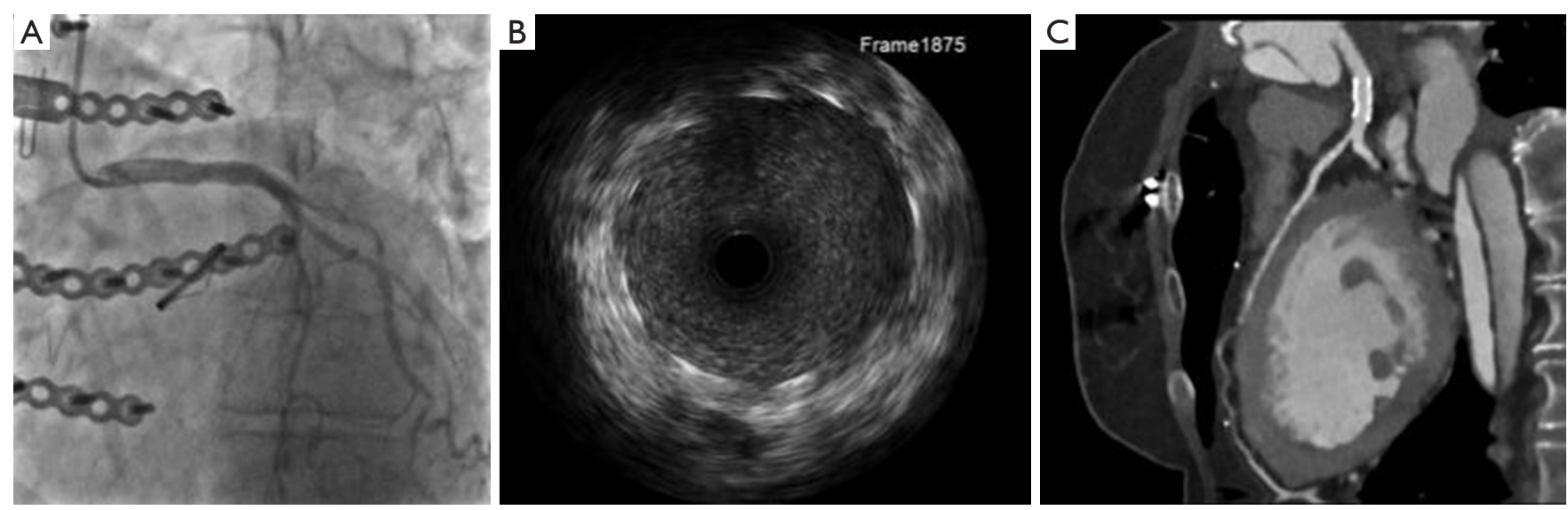

Figure 3 After percutaneous coronary intervention. (A) The final angiographic result; (B) intravascular ultrasound record is depicted showing the well expanded and apposed stent; (C) a curved reconstruction CT image and shows a well conducting stent.

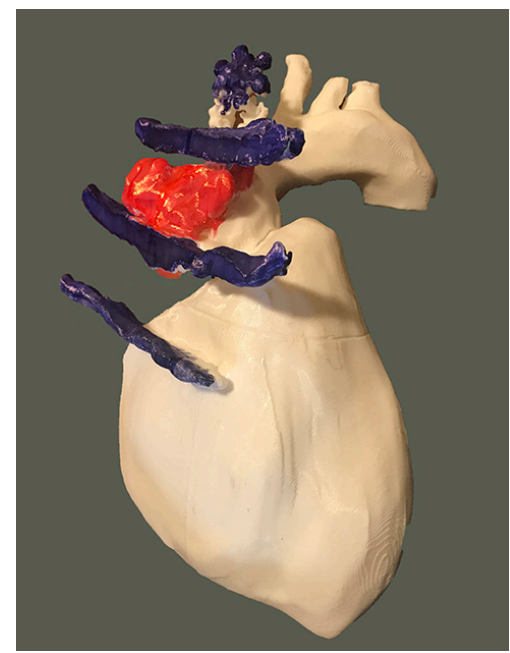

Figure 4 Three-dimensional reconstruction of CT images. The reconstruction of $\mathrm{CT}$ images was printed in $3 \mathrm{D}$, which model was used to evaluate the circumstances regarding the extent of the aortic pseudoaneurysm and its relationship with the chest wall.

reference vascular diameter verification with intravascular ultrasound (IVUS) (Figure 2) and balloon pre-dilation $(4.0 \mathrm{~mm} \times 20 \mathrm{~mm})$, a $5.0 \mathrm{~mm} \times 15 \mathrm{~mm}$ cobalt-chromium drug eluting stent was implanted (Figure 3). Optimization was done with a $6.0 \mathrm{~mm} \times 20 \mathrm{~mm}$ peripheral balloon and controlled with IVUS. One month later, CT control verified a well conducting stent (Figure 3).

During the rehabilitation, the patient started to feel her pulse between the first and second rib. Echocardiography revealed rapid extrathoracic dilation and perfusion of the

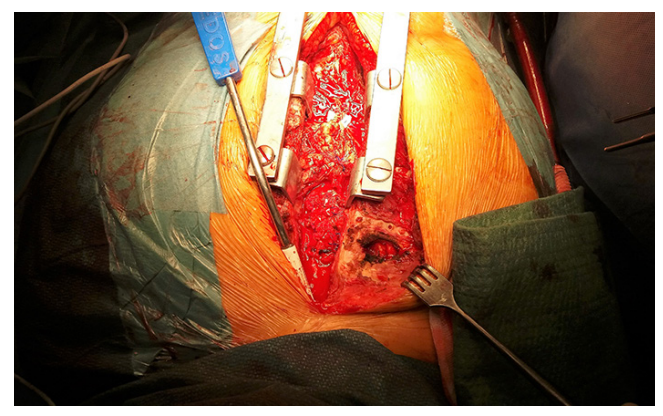

Figure 5 Exploration of the aortic pseudoaneurysm. The threedimensional computed tomography reconstruction showed the adhesion of the titanium plate with the aortic pseudoaneurysm between the right first and second rib (black hole next to the surgical hook). Following careful and precise removal of the synthetic plate, we opened the chest of the patient.

aortic pseudoaneurysm.

Following urgent readmission of the patient, the accurate extension of the pseudoaneurysm could not be characterized by routine CT imaging due to the implanted titanium lamina, as it produced an extended artefact, making the separation impossible. Therefore, using CT angiogram images-three-dimensional (3D) model of the aortic pseudoaneurysm was reconstructed with self-developed MATLAB script and the planned stl file was printed in 3D (Figure 4). As a result, the border zone between titanium lamina and the wall of pseudoaneurysm became precisely separable on the printed 3D model (3) (Figure 4). During the fifth operation (Figure 5), this model was the 


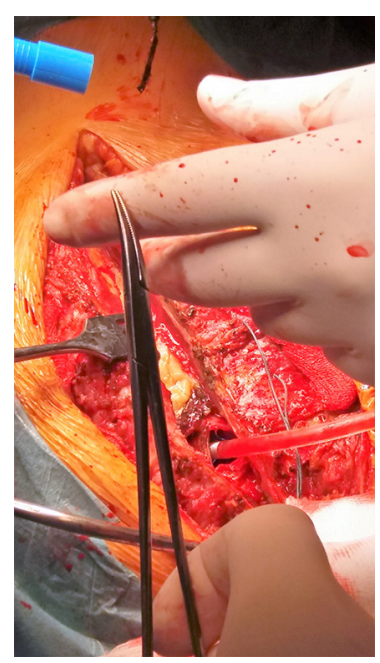

Figure 6 The surgical suction is in the opened grafto-graftal anastomosis during deep hypothermic circulatory arrest (DHCA). All the blood has been removed by blood-gas pump in order to reconstruct the anastomosis and to eliminate the pseudoaneurysm.

basis for the accurate localization of the aneurysmatic bulging and separation of titanium lamina from the aortic pseudoaneurysm sac. After axillo-femoral cannulation, we started to cool down the patient, during which we removed the titanium osteosynthetic plate carefully (Figure 5), since 3D CT reconstruction images showed its adhesion with the aortic pseudoaneurysm. After successful removal of the titanium plates, we opened the chest with an oscillating saw. However, the aortic pseudoaneurysm ruptured as was anticipated (Figure 6), but the patient's body temperature was 16 Celsius degree and cardiopulmonary bypass was already applied. We have explored the lesion, where the 4-0 Prolene was fiberized and ruptured, and the grafto-graftal conduit anastomosis was opened. The anastomosis was reconstructed and we started to warm up the patient after 38 minutes of DHCA. We were able to successfully wean the patient from bypass and close the chest with ZipFix. The patient was extubated on the third day and admitted for rehabilitation 12 days after cardiac surgery, who is currently

Cite this article as: Benke K, Barabás JI, Daróczi L, Sayour AA, Szilveszter B, Pólos M, Lux Á, Székely A, Radovits T, Hartyánszky I, Merkely B, Szabolcs Z. Routine aortic valve replacement followed by a myriad of complications: role of 3D printing in a difficult cardiac surgical case. J Thorac Dis 2017;9(11):E1021-E1024. doi: 10.21037/jtd.2017.10.77 symptomless.

\section{Discussion}

We presented a case of frequent cardiac disease with unique complications following routine cardiac surgery. We also show the emerging importance of $3 \mathrm{D}$ printing technique in chest surgery (4).

\section{Acknowledgements}

The applied MATLAB script and 3D planning of the aortic aneurysm was accomplished by Imre János Barabás.

Funding: This study was supported by the National Research, Development and Innovation Office of Hungary (NKFIH; NVKP-16-1-2016-0017).

\section{Footnote}

Conflicts of Interest: The authors have no conflicts of interest to declare.

Informed Consent: The study participant provided informed consent for the findings of this case to be published.

\section{References}

1. Nkomo VT, Gardin JM, Skelton TN, et al. Burden of valvular heart diseases: a population-based study. Lancet 2006;368:1005-11.

2. Smith CR, Leon MB, Mack MJ, et al. Transcatheter versus surgical aortic-valve replacement in high-risk patients. $\mathrm{N}$ Engl J Med 2011;364:2187-98.

3. Chen N, Zhu K, Zhang H, et al. Three-dimensional printing guided precise surgery for right-sided aortic arch associated with Kommerell's diverticulum. J Thorac Dis 2017;9:1639-43.

4. Yuan D, Luo H, Yang H, et al. Precise treatment of aortic aneurysm by three-dimensional printing and simulation before endovascular intervention. Sci Rep 2017;7:795. 